\title{
STUDY ON THE SYNTHESIS OF DIETHYL METHYL-PHOSPHONITE
}

\author{
Yangyang Jiang ${ }^{1}$, Dailin Li ${ }^{1}$, Fengkai Yan ${ }^{2}$, Chuanbo Dai ${ }^{*}$ \\ ${ }^{1}$ Institute of Petroleum and Chemical, Jilin Institute of Chemical Technology, Jilin 132022, China \\ ${ }^{2}$ Production Department,Chemical Fertilizer Plant of Jilin Petrochemical Corporation, Petro Chinal, Jilin 132021,China. \\ *Corresponding Author Email: daichb@163.com
}

This is an open access article distributed under the Creative Commons Attribution License, which permits unrestricted use, distribution, and reproduction in any medium, provided the original work is properly cited.

\section{ARTICLE DETAILS}

\section{Article History:}

Received 26 June 2018

Accepted 2 July 2018

Available online 1 August 2018

\begin{abstract}
[Aims] Glyphosate is one of the most widely used herbicide in the world, Diethyl methyl-phosphonite(DEMP) is the key intermediate for glyphosate production. Various processes are known for the manufacture of DEMP. However, the substitution reaction has many disadvantages such as low product yield and purity. [Methods] In order to diminish the cost of production of its relevant products, we determine using methylphosphonous dichloride $\left(\mathrm{CH}_{3} \mathrm{PCl}_{2}\right)$, alcohol $\left(\mathrm{CH}_{3} \mathrm{CH}_{2} \mathrm{OH}\right)$ and sodium hydride( $\left.\mathrm{NaH}\right)$ to give DEMP. [Results] The acts of raw materials ratio,reaction temperature, and other factors on the yield were tested. The results showed that the yield was $43.7 \%$ and purity was $86.6 \%$. Its structure was characterized by GC-7980. [Conclusions] $\mathrm{CH}_{3} \mathrm{PCl}_{2}, \mathrm{CH}_{3} \mathrm{CH}_{2} \mathrm{OH}$ and $\mathrm{NaH}$ were used as raw materials to prepare DEMP by a simple and economical operation. The reaction condition is gentle, and cut down the cost of treating by-product.
\end{abstract}

\section{KEYWORDS}

Diethyl methyl-phosphonite, methylphosphonous dichloride, sodium hydride.

\begin{abstract}
1. INTRODUCTION
DEMP is a very important intermediate in organic chemistry. It is widely used in the formation of pesticide, medicine synthesized materials and especially organophosphorus pesticide, DEMP is an important intermediate for the synthesis of glyphosate $[1,2]$. Glyphosate, paraquat and glufosinate are the three major herbicides in the world. Due to its unique mechanism of action, making glufosinate being an excellent alternative since paraquat was banned from more than 20 countries. Additionally, DEMP also used in the field of flame retardants, which can combine three kinds of flame retardants to prevent the polymer from burning. There are many reports about the patent of DEMP synthesis, which can be divided into three main categories.
\end{abstract}

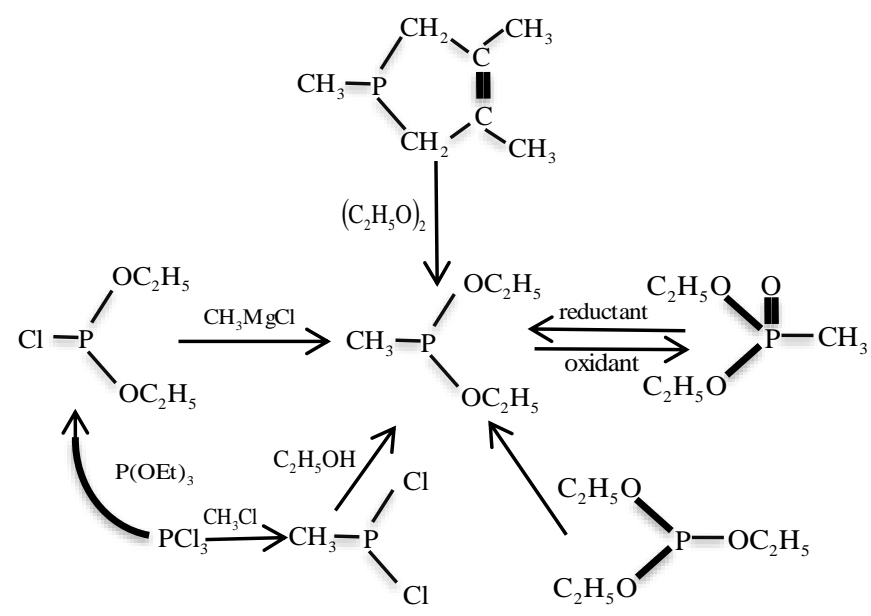

Figure 1: Synthesis of DEMP
The first method is to obtain DEMP from two steps with $\mathrm{PCl}_{3}$ as the raw material. (1) $\mathrm{PCl} 3$ and $\mathrm{P}(\mathrm{OEt})_{3}$ produce $\mathrm{ClP}(\mathrm{OEt})_{2}$ by chemical reaction; (2) $\mathrm{CIP}(\mathrm{OEt})_{2}$ and $\mathrm{CH}_{3} \mathrm{MgCl}$ continue to get DEMP [3-9]. However, the two step reaction is complex, and the first step is to produce more by-products, which will affect the final yield. The second way to produce DEMP is by using $\mathrm{CH}_{3} \mathrm{PCl}_{2}$ as starting material and replacing reaction to get DEMP [1015]. But this requires strict experimental conditions, And the adsorption of hydrochloric acid will produce a large amount of hydrochloride. The third means is the reduction of diethyl methylphosphonate. This method is strict for the selection of reducing agent.

Through the comparison of the above three routes, the results are as follows: On the basis of the second routes, the improvement was made [16]. First, ethanol and odium hydride were reacted, then methylphosphonous dichloride was added to the product. This can reduce the formation of salt and increase production efficiency. And the reducibility of odium hydride can inhibit the oxidation of the products.

\section{EXPERIMENT}

\subsection{Experiment principle}

The Reaction principle is as follows: 


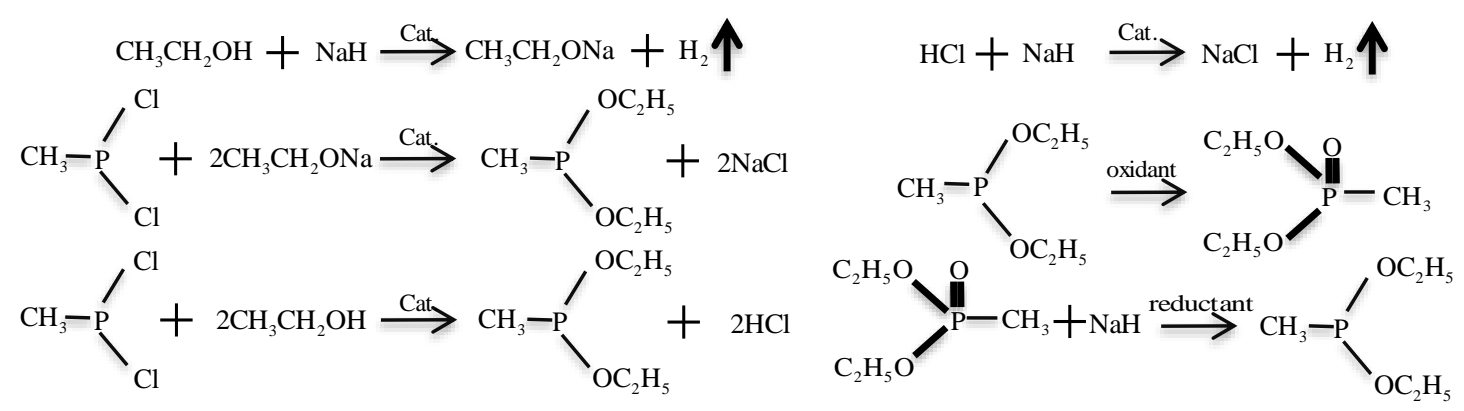

Figure 2: Reaction process diagram

\subsection{Materials and Instruments}

Material: CH3PCl2(98\%); Ethanol; Tetrahydrofuran; Cyclohexane; Pentane; Nitrogen; $\mathrm{NaH}(80 \%)$ Instrument: flask with three necks(500ml); Constant pressure funnel; Electric blender; Thermometer; Filtering apparatus; Balance; Gas-chromatogram(GC-7980)

\section{$2.3 \quad$ Experimental method}

Firstly, Weigh up the pentane $100.0 \mathrm{~g}$, ethanol $21.7 \mathrm{~g}(0.47 \mathrm{~mol})$ and sodium hydride $21.0 \mathrm{~g}$ were added to flask with three necks $(500 \mathrm{ml})$. Creation of vacuum after reaction completed. Then fill in $\mathrm{N}_{2}$ and cool down to $-5^{\circ} \mathrm{C}$. Secondly, To control the temperature of the mixture in flask with three necks at $0{ }^{\circ} \mathrm{C}$, rotator at $600 \mathrm{r} / \mathrm{min}$. Adding the mixture of pentane $(25.0 \mathrm{~g})$ and methylphosphonous dichloride $(21.4 \mathrm{~g} / 0.18 \mathrm{~mol})$, and the generated gas condenses to $-35^{\circ} \mathrm{C}$ to exhaust. When the completion of the dripping, keeping it at room temperature for $5 \mathrm{~h}$. After that, the mixture of product is refined at $125-126^{\circ} \mathrm{C}$. Finally, a colorless and irritant liquid $16.7 \mathrm{~g}$ was obtained. Colorless liquid has been proved to be DEMP by gaschromatogram. The yield of the product is $43.7 \%$ and purity is $86.6 \%$. (Calculation by $\mathrm{CH} 3 \mathrm{PCl} 2$ ).

The gas-chromatogram conditions: Chromatographic column: TM-5 $30 \mathrm{~m} \times 0.32 \mathrm{~mm} \times 0.75 \mu \mathrm{m} 61365702$; Heating program: Initial temperature at $70^{\circ} \mathrm{C}($ Keep $3 \mathrm{~min})$, Increaseing temperature by $30^{\circ} \mathrm{C} / \mathrm{min}$. Final temperature: $180^{\circ} \mathrm{C}($ Keep $5 \mathrm{~min})$; Inlet temperature: $220^{\circ} \mathrm{C}$, Sample size: $0.1 \mu \mathrm{L}$; Peak time: DEMP at 2.212min.

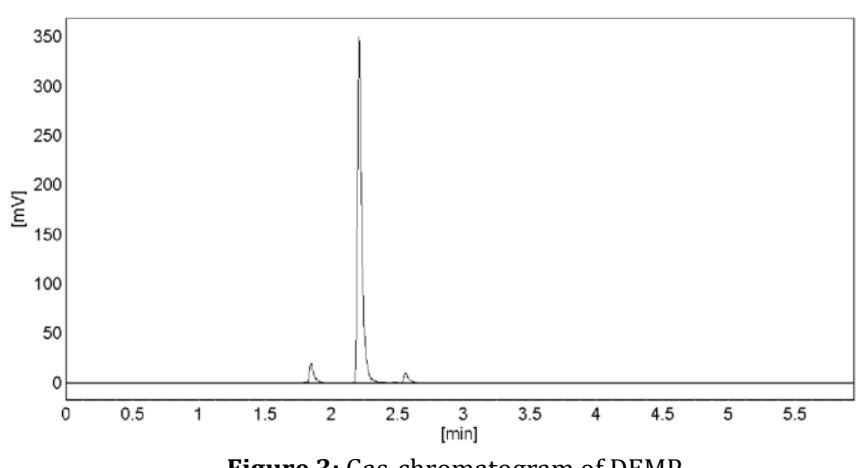

\section{EXPERIMENTAL RESULTS}

The reaction ratio of ethanol and sodium hydride has an effect on the yield of DEMP. Therefore, the reaction with different ratios was designed.

Table 1: Effect of the mole ration to the yield of the DEMP

\begin{tabular}{|cccccc|}
\hline Number & 1 & 2 & 3 & 4 & 5 \\
\hline $\mathrm{n}(\mathrm{CH} 3 \mathrm{CH} 2 \mathrm{OH}): \mathrm{n}(\mathrm{NaH})$ & $1: 0.8$ & $1: 1.0$ & $1: 2$ & $1: 1.4$ & $1: 1.6$ \\
Yield(\%) & $20.7 \%$ & $30.1 \%$ & $38.2 \%$ & $42.8 \%$ & $43.1 \%$ \\
\hline
\end{tabular}

From the above experimental results, it can be seen that when the molar ratio is $n(\mathrm{CH} 3 \mathrm{CH} 2 \mathrm{OH}): n(\mathrm{NaH})=1: 1.6$, the yield of the product is the highest. Therefore, the above results can be used as the known factors to design orthogonal experiments.

\subsection{Factors and levels}

By comparing the results of data analysis, it can be found that some factors affect the yield of DEMP. Factors mainly include solvent type, material ratio, reaction temperature and reaction time. Therefore, the orthogonal experiment of 4 factors and 3 levels is determined. As shown in table 2 .

Table 2: The factors and level of orthogonal experiment

\begin{tabular}{|lllll|}
\hline & Factors & & & \\
\cline { 2 - 5 } level & Ratio(A) & Solvent(B) & Temperature(C) & Time(D) \\
& $($ mol:mol) & (g) & ${ }^{\circ} \mathrm{C}$ & min \\
\hline 1 & $1: 2.5$ & Pentane & 0 & 180 \\
2 & $1: 2.6$ & Tetrahydrofuran & 5 & 240 \\
3 & $1: 2.7$ & Benzene & 10 & 300 \\
\hline
\end{tabular}

Note: The mole ratio in the $\mathrm{B}$ factor is $\mathrm{n}\left(\mathrm{CH}_{3} \mathrm{Cl}_{2} \mathrm{P}\right): \mathrm{n}\left(\mathrm{CH}_{3} \mathrm{CH}_{2} \mathrm{ONa}\right)$

\subsection{Results and analysis}

Selection of $\mathrm{L}_{9}\left(3^{4}\right)$ orthogonal forms in the experiment, And the experimental scheme and results are shown in Table 3. 
Table 3: The factors and level of orthogonal experiment

\begin{tabular}{|c|c|c|c|c|c|}
\hline \multirow{3}{*}{ Number } & \multicolumn{4}{|l|}{ Factors } & \multirow{3}{*}{ Yield(\%) } \\
\hline & Solvent(A) & Ratio(B) & $\begin{array}{l}\text { Temperature }(\mathrm{C} \\
\text { ) }\end{array}$ & Time(D) & \\
\hline & (g) & (mol:mol) & ${ }^{\circ} \mathrm{C}$ & $\min$ & \\
\hline 1 & 1 & 1 & 1 & 1 & $26.96 \%$ \\
\hline 2 & 1 & 2 & 2 & 2 & $41.82 \%$ \\
\hline 3 & 1 & 3 & 3 & 3 & $37.93 \%$ \\
\hline 4 & 2 & 1 & 2 & 3 & $43.52 \%$ \\
\hline 5 & 2 & 2 & 3 & 1 & $36.12 \%$ \\
\hline 6 & 2 & 3 & 1 & 2 & $36.81 \%$ \\
\hline 7 & 3 & 1 & 3 & 2 & $27.31 \%$ \\
\hline 8 & 3 & 2 & 1 & 3 & $33.27 \%$ \\
\hline 9 & 3 & 3 & 2 & 1 & $32.49 \%$ \\
\hline $\mathrm{K} 1$ & 1.0671 & 0.9779 & 0.9704 & 0.9557 & \\
\hline $\mathrm{K} 2$ & 1.1645 & 1.1121 & 1.1783 & 1.0594 & \\
\hline K3 & 0.9307 & 1.0723 & 1.0136 & 1.1472 & \\
\hline $\mathrm{k} 1$ & 0.3557 & 0.3260 & 0.3235 & 0.3186 & \\
\hline k2 & 0.3882 & 0.3707 & 0.3928 & 0.3531 & \\
\hline k3 & 0.3102 & 0.3574 & 0.3379 & 0.3824 & \\
\hline Range & 0.078 & 0.045 & 0.069 & 0.064 & \\
\hline Sequence & $A>C>D>B$ & & & & \\
\hline Level & $\mathrm{A}_{2}$ & $\mathrm{~B}_{1}$ & $\mathrm{C}_{2}$ & $\mathrm{D}_{3}$ & \\
\hline Combination & $\mathrm{A}_{2} \mathrm{~B}_{1} \mathrm{C}_{2} \mathrm{D}_{3}$ & & & & \\
\hline
\end{tabular}

Note: K: The sum of the experimental percentages corresponding of the level

$\mathrm{k}$ : The average number of the experimental percentages corresponding of the level

\subsection{Verification experiment}

The technological conditions for the synthesis of DEMP was determined by orthogonal experiments. In order to verify the reproducibility of orthogonal experiments, five repeatability experiments were carried out under optimized process conditions. The results of the experiment are shown in Table 4.

Table 4: Conversion rate, selectivity, yield of five experiences

\begin{tabular}{|llll|}
\hline Number & $\begin{array}{l}\text { Conversion } \\
(\%)\end{array}$ & Selectivity (\%) & Yield (\%) \\
1 & 55.5 & 76.9 & 42.5 \\
2 & 56.2 & 76.9 & 43.2 \\
3 & 57.7 & 76.5 & 44.1 \\
\hline
\end{tabular}

It can be seen from the experiment that the conversion rate and selectivity of methylphosphonous dichloride in the five groups of experiments are similar. The yield of DEMP was $42.5 \%-44.1 \%$. The experimental results are verified.

\section{CONCLUSION}

Synthesis of DEMP by the reaction of $\mathrm{CH}_{3} \mathrm{PCl}_{2}$ and $\mathrm{CH}_{3} \mathrm{CH}_{2} \mathrm{ONa}$, which in Pentane Solution. Optimum condition for synthesis: $\mathrm{n}\left(\mathrm{CH}_{3} \mathrm{PCl}_{2}\right): \mathrm{n}\left(\mathrm{CH}_{3} \mathrm{CH}_{2} \mathrm{ONa}\right)=1: 2.6$; Reaction Temperature: $0^{\circ} \mathrm{C}$. DEMP was obtained by optimizing the above reaction conditions, and the yield is up to $43.7 \%$. The reaction process is mild and easy to operate, And it can avoid the subsequent treatment of hydrochloride formed in the traditional process. Additionally, $\mathrm{NaH}$ can inhibit the oxidation of products. Therefore, the production of DEMP by this method has great industrial prospect.

\section{ACKNOWLEDGMENTS}

Thank Professor Chuanbo Dai and other teachers for their valuable advice on my thesis, so that I can finish this thesis successfully. Thank Ms. Wang for helping me with my life during my thesis.

\section{REFERENCES}

[1] Ford-Moore, A.H., Bebbington, A. 1974. Improvements in the Manufacture of Organic Phosphorus Compounds [P], GB1375690, 11-27.
[2] Xu, L. 2017. Study on the Synthesis of Glufosinate [D]. Zhejiang University.

[3] Collins, D.J., Drygala, P.F., Swan, J.M. 1983. Organophosphorus compounds. XIX. Synthesis of 2,3-Dihydro-1 H-1,2-benzazaphosphole 2oxides, variously substituted on nitrogen and phosphorus, by N-P cyclization of zwitterionic intermediates [J]. Australian Journal of Chemistry, 36.

[4] Schmerling, L. 1961. Preparation of alkylphosphorus dichloride: US, US 2986579 A[P].

[5] Coates, H., Morris, D. 1974. Preparation of Complex aluminum Compounds and alkyl Phosphorus Halides [J]. Journal of the International Aids Society, 13 (13).

[6] Palacios, F., Aparicio, D., Santos, J.M.D.L. 2001. Regioselective alkylation reactions of hydrazones derived from phosphine oxides and phosphonates. Synthesis of phosphorus substituted 1-amino-pyrrolones, pyridinones and pyrroles [J]. Cheminform, 32 (33), 1961-1972.

[7] Kaiser, E., Sporar, L. 1959. Preparation of grignard reagents: US $2881225 \mathrm{~A}[\mathrm{P}]$.

[8] Ding, C. 2016. Study on synthesis process of methyl phosphodiethyl phosphate [J]. Journal of Zhejiang University of Technology, 44 (2), 150153.

[9] Wang, H. 2005. Synthesis process of diethyl phosphonate [J]. The New Century Of Agrochem, 35 (8), 23-23.

[10] Maier, L. 1962. Process for preparing organophosphorus halides: US, US 3057917A [P].

[11] Staendeke, H. 1973. Production of trialkylphosphines: US, US $3760001 \mathrm{~A}[\mathrm{P}]$.

[12] Pianfetti, J.A., Quin, L.D. 1962. Formation of Phosphonous Dichlorides by Alkylation of Phosphorus Trichloride with Methane or Ethane [J]. Journal of the American Chemical Society, 84 (5), 851-854.

[13] Lichtenberg, H.C. 1959. Production of esters of phosphonous and phosphinous acids: US, US 2903475 [P].

[14] Miles, J.A., Balthazor, T.M., Nufer, H.L. 1979. Chem Inform Abstract:Improved, reproducible Procedures for the Preparation of Diethyl Methylphosphonit [J]. Cheminform, 10 (31), 11-16. 
[15] Wang, Y. 2004. 0,0-Diethyl Methylphosphonite [D]. Zhejiang University Of Technology.

[16] Li, Y. 2012. A Method to Prepare Glufosinate. Agrochemicals, 51 (1), 11-13.

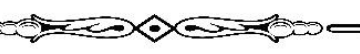

